\title{
Comment on: "A Single Dose-Escalation Study to Evaluate the Safety and Pharmacokinetics of Orally Administered Des-aspartate Angiotensin I in Healthy Subjects"
}

\author{
Nuggehally R. Srinivas ${ }^{1}$
}

Published online: 30 November 2016

(C) The Author(s) 2016. This article is published with open access at Springerlink.com

Des-aspartate angiotensin I (DAA-I) is a short-acting peptide molecule comprising nine amino acids, whose main role is to block angiotensin II via agonistic activity on the angiotensin AT1 receptor [1]. Lee et al. recently reported the safety, tolerability and pharmacokinetics of DAA-1 in healthy subjects who received single escalating doses of DAA-1 in an extemporaneously prepared oral formulation [2]. This study in particular assumes importance primarily because hitherto no such human clinical pharmacology data pertaining to DAA-1 have been published [2].

The safety and tolerability data gathered in this study showed no inadvertent effects and/or adverse events associated with DAA-1. However, the lack of differentiation in the single-dose pharmacokinetics of the examined three active doses in relation to placebo [2] poses a challenge in developing a cohesive clinical development plan for the advancement of DAA-1. Because of the rapid degradation of DAA-1, it was not expected that the first exogenous dose of DAA-1 at $0.08 \mathrm{mg} / \mathrm{kg}$ would show appreciable plasma levels in the human subjects [2]. Interestingly, the other two higher doses of DAA-1 (i.e., 0.7 and $1.5 \mathrm{mg} / \mathrm{kg}$ ) appeared to be equally rapidly metabolized, resulting in no appreciable systemic levels of DAA-1 [2]. Perhaps one limitation of the study, as pointed out by the authors, was related to the frequency of pharmacokinetic sample time

This comment refers to the article available at doi:10.1007/s40268016-0143-y. \section{.}


frequency of multiple-dosing regimens? What would be the cap, if any, on the highest dose of DAA- 1 to be administered in the study? These questions are rather difficult to answer, especially if the orally administered DAA-1 is rapidly metabolized and/or de-stabilized in the gastrointestinal tract.

Therefore, as a drug developer it may become important to find innovative ways to tackle such tricky issues. Prior to investment of resources for the whole clinical development program, it may be vital to ascertain the proof of concept of the desired effect of DAA-1. Although the authors' suggestion of using circulatory prostaglandin entities such as prostaglandin E2 $\left(\mathrm{PGE}_{2}\right)$ or prostaglandin $\mathrm{I} 2\left(\mathrm{PGI}_{2}\right)$ as target biomarkers may be potentially considered [2], it would still fall short of the much desired confirmatory pharmacological activity of DAA-1 for allocation of resources for full-scale drug development. Hence, to better understand the pharmacodynamics of exogenous DAA-1 and obtain proof of concept of its pharmacological activity, one might consider DAA-1 given in a combination regimen with another agent, using an established surrogate marker such as blood pressure.

In order to establish the proof of concept of DAA-1, two other companion classes of drugs, namely, angiotensinconverting-enzyme inhibitors (ACEIs) and angiotensin receptor blockers (ARBs), may be potentially considered. The design may involve the addition of DAA- 1 to either an ACEI- or ARB-stabilized regimen that may help in the reduction of the stable doses of either ACEI or ARB companion drug in the relevant patient population. Perhaps, the highest dose of DAA-1 tested in the single-dose escalating study (i.e., $1.5 \mathrm{mg} / \mathrm{kg}$ ) could potentially be added to the stable dose regimen of either ACEI or ARB in a twice daily (bid) dosing regimen of DAA-1 with concomitant reduction in the respective dose of either the ACEI or ARB. Alternatively another design may be to randomize a group of patients on stable doses of either ACEI or ARB to two experimental groups: one group would continue to be on the stable dose of either of the two drugs, while the other group would receive approximately $50 \%$ of the stable dose of either of the two drugs along with the highest tested dose of DAA-1 (bid regimen). Regardless of the design adopted, after a specific time period, the measurement of blood pressure as the surrogate would establish the proof of concept of DAA-1.

Overall, development of peptide drugs via the oral route represents a considerable challenge as manifested for other drugs, most notably insulin [8]. Hence, as a first step it may be crucial to understand the proof of concept whether such a route (i.e., oral) is amenable for DAA- 1 and what may be the minimal dose requirement/regimen to achieve the proof of concept.

\section{Compliance with Ethical Standards}

Funding No funding was received to prepare the manuscript.

Conflict of interest The author has no conflict of interest to declare regarding the contents of the manuscript. The manuscript was prepared to facilitate scientific exchange on a topic of interest in clinical pharmacology.

Open Access This article is distributed under the terms of the Creative Commons Attribution-NonCommercial 4.0 International License (http://creativecommons.org/licenses/by-nc/4.0/), which permits any noncommercial use, distribution, and reproduction in any medium, provided you give appropriate credit to the original author(s) and the source, provide a link to the Creative Commons license, and indicate if changes were made.

\section{References}

1. Sim MK. Des-aspartate-angiotensin I, a novel angiotensin AT(1) receptor drug. Eur J Pharmacol. 2015;760:36-41.

2. Lee KO, Khoo CM, Chowbay B, Chan YH, Sim MK. A single dose-escalation study to evaluate the safety and pharmacokinetics of orally administered des-aspartate angiotensin I in healthy subjects. Drugs R D. 2016;16:317-326. doi:10.1007/s40268-0160143-y.

3. Loh WM, Ling WC, Murugan DD, et al. Des-aspartate angiotensin I (DAA-I) reduces endothelial dysfunction in the aorta of the spontaneously hypertensive rat through inhibition of angiotensin II-induced oxidative stress. Vascul Pharmacol. 2015;71:151-8.

4. Wong YC, Sim MK, Lee KO. Des-aspartate-angiotensin-I and angiotensin IV improve glucose tolerance and insulin signalling in diet-induced hyperglycaemic mice. Biochem Pharmacol. 2011;82:1198-208.

5. Loh WM, Ling WC, Murugan DD, et al. Des-aspartate angiotensin I (DAA-I) reduces endothelial dysfunction in the aorta of the spontaneously hypertensive rat through inhibition of angiotensin II-induced oxidative stress. Vascul Pharmacol. 2015;71:151-8.

6. Brown LR. Commercial challenges of protein drug delivery. Expert Opin Drug Deliv. 2005;2:29-42.

7. Reis CP, Silva C, Martinho N, Rosado C. Drug carriers for oral delivery of peptides and proteins: accomplishments and future perspectives. Ther Deliv. 2013;4:251-65.

8. Wong CY, Martinez J, Dass CR. Oral delivery of insulin for treatment of diabetes: status quo, challenges and opportunities. J Pharm Pharmacol. 2016;68:1093-108. 